\title{
Changing use of the emergency department by the elderly in the United Arab Emirates, 1989 and 1999
}

S.A. Margolis' and R.L. Reed'

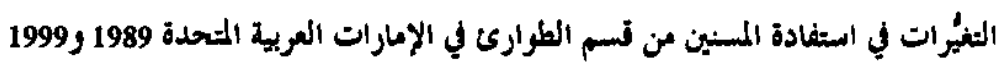

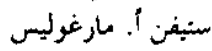

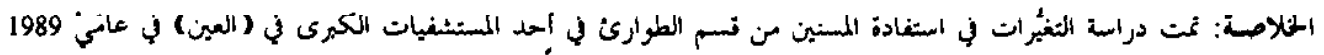

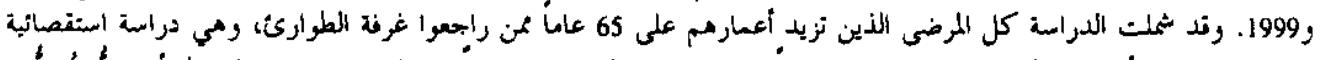

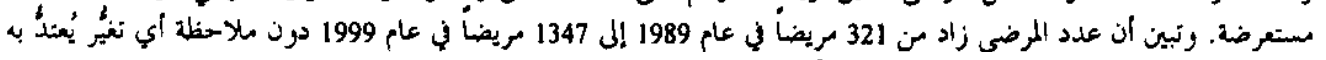

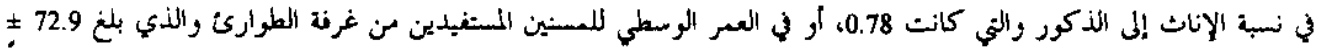

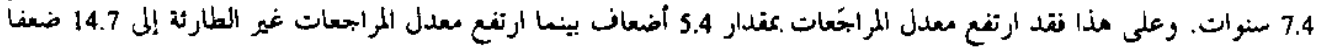

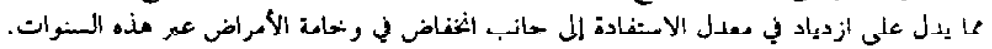

ABSTRACT Changes in use by the elderly of the emergency department of a major hospital in Al-Ain in the years 1909 and 1999 were examined. All parlents aged 65 years or older who attended the emergency room were included in this cross-sectional survey. Patient numbers rose from 321 in 1989 to 1347 in 1999 with no significant change in the female to male ratio of 0.78 or the mean age of the elderly attendees $72.9 \pm 7.4$ years. Attendance rose 5.4 fold while non-urgent attondanco roso 14.7 fold, demonstrating rising use but falling iliness severity over time.

Evolution de l'utilisation du service des urgences par les personnes âgées aux Emirats arabes unis, 1989 et 1999

RESUME On a examiné les modifications intervenues dans l'utilisation par les personnes âgées du service des urgences d'un grand hopltal a Al-Aln durant les annees 1989 et 1999. Tous les patients âgés de 65 ans ou plus qui se sont rendus au service des urgences ont été inclus dans cette enquête transversale. Le nombre des patients est passé de 321 en 1989 à 1347 en 1999, sans changement significatif dans le rapport hommes/femmes qui était de 0,78 ou dane l'âge moyen des personnes âgées se rendant dans ce service, à savoir $72,9 \pm 7,4$ ans. La fréquentation du service des urgences a augmenté de 5,4 fois tandis que la fréquentation des autres services a été multipliée par 14,7, montrant une augmentation de l'utilisation mais une diminution de la sévérité de la maladie au fil du temps.

'Department of Family Medicine, United Arab Emirates University, Al-Ain, United Arab Emirates.

Received: 11/04/01; accepted: 16/09/01

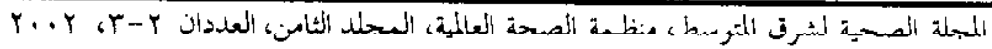




\section{Introduction}

Although the elderly have a higher rate of health care use than other age groups, there is a low level of awareness of their special needs in the emergency room (ER) reflected by the paucity of research in this area [1-4]. Little information is available concerning the situation in countries that do not have an advanced economy. Mesken et al. found in Katmandu, Nepal, a developing nation, that $30 \%$ of presentations to ER were for injury, $27 \%$ of presentations resulted in admission, $<1 \%$ of patients had laboratory teste and no physicians had ER qualifications [5]. The Kirsch et al. study in Port-of-Spain, Trinidad and Tobago found that $42 \%$ of all presentations to ER were for injury, $41 \%$ were admitted, $9 \%$ had laboratory tests, there were no medical records and only one physician had completed any residency training [6]. Furthermore, there are no data from countries with a newly developed economy or those experiencing rapid, sustained development with a high per capita income [7].

The United Arab Emirates (UAE) is a union of seven sovereign sheikhdoms formed in 1971. The lifestyle of UAE citizens changed little over hundreds of years until modern development began 40 years ago. The UAE has been experiencing a booming petroleum-based economy since the $1970 \mathrm{~s}$, which has supported a dramatic surge in modernization and development such that UAE citizens now have one of the highest per capita incomes in the world $[8,9]$.

The first hospital was built in 1949 hut it was not until the late 1970 s that a modern health infrastructure began to be created. The health care system has since undergone rapid development including the opening of a medical school in 1985 [10]. By the late $1990 \mathrm{~s}$, a sophisticated primary health care system had been established. Expatriate physicians provide the majority of health care delivery and come from numerous different countries throughout the world.

As with other countries undergoing rapid development, there is an attempt to blend the old with the new. In a society where traditional healers were the sole custodians of health care until recently, many people, especially the elderly, continue to consult their traditional healers while learning to embrace Western medicine [ $1 I]$.

This study attempts to document the changes in the use of the ER by the elderly over the 10-year period 1989-1999. This period parallels dramatic changes in health care provision from a developing hospitalfocused structure to a sophisticated vertically integrated system offering primary, secondary and tertiary care. In particular, medical care for the elderly has begun to diverge from general medical care towards a separate specialty area. In 1989, the ER provided much of the medical care of the elderly, including assessment, intervention and referral. However, by 1909 the ER was providing a more systematic approach, using more of the principles of geriatric care that are routinely used by specialized geriatric assessment units. From the emerging trends, areas of need and potential intervention strategies can be identified, especially towards the establishment of comprehensive geriatric services in the UAE.

\section{Methods}

This study was a cross-sectional survey. The data were abstracted from the ER daybook by three trained abstractors who were registered nurses working in the ER. This handwritten ledger, which is completed by ER staff during each patient's visit, 
was the only record available as no computerized data existed. The components abstracted were those listed in this data source: age, sex, date, time of arrival, time of departure, triage code ascertained on arrival, diagnosis at discharge from $\mathrm{ER}$ and whether during their ER stay the patient received laboratory tests, $X$-ray, intravenous access, specialist consultution, admission or transfer. The four-level triage code system used by the hospital was: (1) lifethreatening, e.g. cardiorespiratory arrest; (2) acute, e.g. chest pain or cerebrovascular event with a conscious and alert patient; (3) urgent, e.g. undiagnosed abdominal pain with stable vital signs; and (4) non-urgent, e.g. upper respiratory tract infection.

All elderly people (defined as those aged 65 years and older [12]) who were seen in the ER of a major hospital in Al-Ain, UAE in the years 1989 and 1909 were included. In 1989 , those aged $65+$ years numbered $19200(1.2 \%$ of the total population of 1633200 ) with a female:male ratio of 0.96 [13]. In 1999, those aged 65+ years numbered $32000(1.1 \%$ of the total population of 2938000 ), with a female:male ratio of 0.89 [14]. The life expectancy at birth was estimated in 2000 to be 71.6 years for males and 76.6 years for females [15]. The low proportion of the population aged 65+ years and the gender ratio below 1 are similar to findings in other newly developed nations [15].

The study was in Al-Ain, whose total population grew from 211500 in 1989 (13\% of the total UAE population) to 359100 in 1999 (12.2\% of the total UAE population) $[13,14]$. Unfortunately, no age distribution by region has been published. Throughout the period under study, the ER caseload in this health district was shared with only one other hospital. The ER was staffed entirely by expatriate doctors, mostly from Western countries; several had ER board certification, many had undergone partial ER training and all had participated in residency programmes. There was an active continuing medical education programme.

The United Arab Emirates University Faculty of Medicine and Health Sciences Research Ethics Committee and Tawam Hospital, both of which comply with the ethical rules for human experimentation that are stated in the Declaration of Helsin$\mathrm{ki}$, approved the project.

SPSS version 10 and Epi-Info version 6 were used for statistical analysis. Comparative statistics were calculated using chisquared analysis for categorical variables and analysis of variance for continuous variables. The level of elinical significanec was set at $P<0.05$.

\section{Results}

All patient entries were included in the study analysis. Data validity was confirmed by demonstrating $>95 \%$ agreement between abstractors in a systematic sample of 100 patients.

The number of elderly individuals seen in the ER rose from 321 in 1989 to 1347 in 1999. The mean age \pm standard deviation was $72.9 \pm 7.4$ years and the female to male ratio was 0.78 . The age and gender ratios statistically did not significantly change between 1989 and 1999 .

There was a statistically significant rise in both the absolute number of elderly attendances (491 in 1989 to 2629 in 1999) and in the proportion of elderly in total attendances (3\% in 1989 to $5 \%$ in 1999) $(P<$ 0.001 ) (Table 1). The mean number of visits per person per year rose significantly from $1.8 \pm 1.7$ in 1989 to $3.3 \pm 5.0$ in 1999 $(P<0.001)$. The severity of illness on ar-

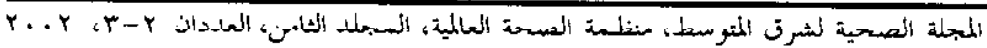




\begin{tabular}{|c|c|c|c|c|c|}
\hline \multirow[t]{2}{*}{ Data on attendances } & \multicolumn{2}{|c|}{1989} & \multicolumn{2}{|c|}{1999} & \multirow[t]{2}{*}{ Pvalues } \\
\hline & No. & $\%$ & No. & $\%$ & \\
\hline \multicolumn{6}{|l|}{ Patients } \\
\hline All ages & 17184 & & 55261 & & \\
\hline $\begin{array}{l}\text { Elderly (\% of all } \\
\text { attendances that year) }\end{array}$ & 491 & 3 & 2629 & 5 & $<0.0001$ \\
\hline \multicolumn{6}{|l|}{ Diagnosis } \\
\hline Respiratory & 82 & 17 & 562 & 21 & 0.02 \\
\hline Cardiovascular & 83 & 17 & 385 & 15 & 0.20 \\
\hline Aboominal & 63 & 13 & 410 & 10 & 0.12 \\
\hline Musculoskeletal/trauma & 89 & 18 & 317 & 12 & 0.0002 \\
\hline $\begin{array}{l}\text { Genitourinary/breast } \\
\text { Nourological/ }\end{array}$ & 53 & 11 & 209 & 8 & 0.04 \\
\hline cerebrovascular/psychiatric & 40 & 8 & 134 & 5 & 0.007 \\
\hline Metabolic & 20 & 4 & 120 & 5 & 0.63 \\
\hline $\begin{array}{l}\text { ENT/ophthalmological/ } \\
\text { dental/dermatological }\end{array}$ & 14 & 3 & 120 & 5 & 0.09 \\
\hline Haematology/oncology & 11 & 2 & 31 & 1 & 0.06 \\
\hline $\begin{array}{l}\text { Referred directly } \\
\text { to primary care }\end{array}$ & 7 & 1 & 284 & 11 & $<0.0001$ \\
\hline Other & 29 & 6 & 57 & 2 & $<0.0001$ \\
\hline \multicolumn{6}{|l|}{ Triage code } \\
\hline 1. Life-threatening & 7 & 1 & 14 & 0.5 & $0.04^{*}$ \\
\hline 2. Acute & 99 & 20 & 171 & 7 & $<0.0001$ \\
\hline 3. Urgent & 316 & 64 & 1431 & 54 & $<0.0001$ \\
\hline 4. Non-urgent & 69 & 14 & 1013 & 30 & $<0.0001$ \\
\hline \multicolumn{6}{|l|}{ Procedures carried out } \\
\hline ER laboratory tests & 209 & 43 & 1058 & 40 & 0.34 \\
\hline ER $X$-ray & 163 & 31 & 856 & 33 & 0.54 \\
\hline ER intravenous access & 110 & 22 & 908 & 35 & $<0.0001$ \\
\hline ER specialist consultation & 239 & 49 & 845 & 32 & $<0.0001$ \\
\hline Admitted from $\mathrm{ER}$ & 205 & 42 & 513 & 20 & $<0.0001$ \\
\hline Transferred from EA & 77 & 16 & 214 & 8 & $<0.0001$ \\
\hline \multicolumn{6}{|l|}{ Length of stay in ER (minutes) } \\
\hline $5-120$ & 409 & 83 & 1827 & 69 & $<0.0001$ \\
\hline$>120$ & 82 & 17 & $\pi 73$ & 29 & $<0.0001$ \\
\hline
\end{tabular}

${ }^{2} \chi^{2}$ analysis. ${ }^{b}$ Fischer exact test.

$P<0.05$ was considered significant. $E N T=$ ear, nose and throat.

rival to ER as reflected by the triage code fell significantly from 1989 to 1999.

The most significant change was an increase in non-urgent attendances among the elderly from $14 \%$ to $39 \%(P<0.0001)$
(Table 2). These attendances were mostly in the morning and in 1989 were less common in winter. The mean number of visits per person per year for non-urgent attendance rose from $1.08 \pm 0.27$ in 1989 to 


\begin{tabular}{|c|c|c|c|c|c|}
\hline \multirow[t]{2}{*}{ Attendance } & \multicolumn{2}{|c|}{1989} & \multicolumn{2}{|c|}{1999} & \multirow[t]{2}{*}{ P-value } \\
\hline & No. & $\%$ & No. & $\%$ & \\
\hline Total triage $\operatorname{cod} \theta 4$ & 69 & & 1013 & & \\
\hline \multicolumn{6}{|l|}{ Arrival: time of day } \\
\hline Morning $(07: 00-12: 59)$ & 34 & 49 & 426 & 42 & 0.24 \\
\hline Afternoon (13:00-18:59) & 20 & 29 & 268 & 26 & 0.46 \\
\hline Evening (19:00-23:59) & 8 & 12 & 221 & 22 & 0.05 \\
\hline Night (24:00-06:59) & 7 & 10 & 98 & 10 & 0.90 \\
\hline \multicolumn{6}{|l|}{ Arrival: season } \\
\hline Summer (June, July, Augusi) & 15 & 22 & 235 & 23 & 0.78 \\
\hline \multicolumn{6}{|l|}{ Autumn (September, October, } \\
\hline November) & 18 & 26 & 252 & 25 & 0.82 \\
\hline \multicolumn{6}{|l|}{ Winter (December, January, } \\
\hline February) & 12 & 17 & 299 & 30 & 0.03 \\
\hline Spring (March, April, May) & 24 & 35 & 227 & 22 & 0.02 \\
\hline \multicolumn{6}{|l|}{ Diagnosis catogony } \\
\hline Respiratory & 6 & 9 & 26 & 3 & $0.01^{\mathrm{b}}$ \\
\hline Cardiovascular & 13 & 19 & 169 & 17 & 0.64 \\
\hline Abdominal & 9 & 13 & 150 & 15 & 0.69 \\
\hline Musculoskeletal/trauma & 13 & 19 & 123 & 12 & 0.10 \\
\hline Genitourinary/breast & 4 & 6 & 91 & 9 & 0.37 \\
\hline \multicolumn{6}{|l|}{ Neurological/cerebrovascular/ } \\
\hline psychiatric & 4 & 6 & 47 & 3 & $0.42^{4}$ \\
\hline Metabolic & 1 & 1 & 35 & 3 & $0.32^{\circ}$ \\
\hline \multicolumn{6}{|l|}{ ENT/ophthalmological/dental/ } \\
\hline dermatological & 34 & 83 & 8 & 0.25 & \\
\hline Haematology/oncology & 4 & 6 & 7 & 1 & $0.004^{b}$ \\
\hline Referred directly to primary care & 7 & 10 & 262 & 26 & 0.004 \\
\hline Other & 5 & 7 & 20 & 2 & 0.02 \\
\hline
\end{tabular}

${ }^{\mathrm{a}} \chi^{2}$ test. ${ }^{b}$ Fischer exact tes!.

$\mathrm{P}<0.05$ was considered significant.

$E N T=$ ear. nose and throat.

$1.37+1.12$ in $1999(P=0.04)$. Most nonurgent attendances were for cardiovascular, abdominal or musculoskeletal/trauma problems. However, in 1999 there was a significant rise in non-urgent attendances "referred directly to primary care" from $10 \%$ to $26 \%$, which then became the leading diagnosis $(P=0.004)$. This statistically significant fall in illness severity was seen across all age groups.
The most statistically significant change for all elderly attendees in primary diagnosis category on discharge from ER was a rise in those referred directly to primary care $(1 \%$ in 1989 to $11 \%$ in $1999, P<$ 0.0001 ) (Table 1). Other significant changes included a fall in musculoskeletal/trauma ( $18 \%$ in 1989 to $12 \%$ in $1999, P=0.0002$ ) and a rise in respiratory illness from $17 \%$ in 1989 to $21 \%$ in $1999(P=0.02)$. There was

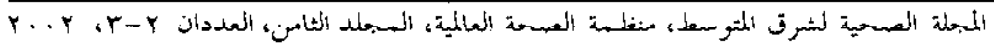


a fall in the number of patients requiring specialist consultations and being admitted or transferred to other institutions. This paralleled the fall in illness severity although the rate of diagnostic testing was unchanged, and the rate of establishing intravenous access rose significantly.

\section{Discussion}

This study has demonstrated a substantial change between 1989 and 1999 in both the number and nature of elderly people attending the ER. As demonstrated in Tables 1 and 2, in 1989 the elderly accounted for few attendances, had a high degree of illness severity and were often admitted. In contrast, the elderly in 1999, whose demographics were unchanged, were attending the ER in larger absolute and proportional numbers but were significantly less ill. In particular, the number of non-urgent visits rose 14.7 fold compared to a rise in all visits of 5.4 fold and a general population increase of older people of 1.7 fold.

The fall in illness severity is paralleled by a fall in specialist consultation rates and admissions to hospital. This decline suggests that in 1999 many people, including the clderly, chose the ER as their sourec of non-urgent medical care, despite the presence of an expanding primary care sector undergoing substantial development. This may explain the fall in the proportion of cases seen with emergency problems such as musculoskeletal/trauma and the rise in respiratory illness with time.

Despite the decline in illness severity, there was no decline in ER investigations performed for elderly patients. This possibly reflects the worldwide trend for a higher rate of investigations in the ER since 1989. Similarly, the rise in intravenous access rates possibly reflects this modern ER practice.
The rise between 1989 and 1999 in the absolute number of attendances by older people may reflect a growing acceptance of Western-style medical care in this traditional society. Of those attending for urgent care, there may have been an increasing acceptance of presenting earlier in the course of their illness. Although there was no evidence to suggest a significant change. in the overall prevalence of disease, we might have expected a decline, especially for infectious disease, as a result of improved sanitation and nutrition.

The ER aims to provide both care for those with emergency medical conditions and others with non-emergency problems unable to access alternative care [16]. However, athough common practice, the ER is not an ideal location for the latter form of care, for clinical and economic reasons $[17,18]$. Hence, the rising use of the ER for non-urgent care as seen in this study is cause for concern. Perhaps this decline of illness severity on presentation to the ER, which parallels development and modernization of the health care system, reflects changes that occurred in Western countries at some time in the past. As most of these patients were seen at times when primary care clinics were open and their attendance was evenly distributed across the seasons, an appropriate course of action may be a public education campaign on the different roles of the ER and primary care centres to direct people to the appropriate place to seek care.

This study found that in the UAE, a rapidly developing country, ER attendance by the elderly significantly changed over time, with rising use and falling illness severity. The next phase in development for a country such as the UAE is the further development of medical services for the elderly to encompass a comprehensive system of health care that includes life-threatening and ternuinal conditions. 


\section{References}

1. Witzke DB, Sanders AB. The development and evaluation of a geriatric emergency medicine curriculum. The SAEM Geriatric Emergency Medicine Task Force. Academy of Emergency Medicine, 1997, 4(3):219-22.

2. Singal $B M$ et al. Geriatric patient emergency visits. Part I: Comparison of visits by geriatric and younger patients. Annals of emergency medicine, 1992, 21(7): $802-1$.

3. Sanders AB, Morley JE. The older person and the emergency department. Journal of the American Geriatric Society, 1993, 41(8):880-2.

4. Sanders AB. Care of the elderly in emergency departments: conclusions and recommendations. Annals of emergency medicine, 1992, 21(7):830-4.

5. Meskin S et al. Delivery of emergency medical services in Kathmandu, Nepal. Annals of emeroency medicine. 1997. 29(3):409-14.

6. Kirsch TD et al. Epidemiology and practico of emergency modicino in a dovaloping country. Annals of emergency medicine, 1995, 26(3):361-7.

7. Gardiner WE. Developing a quallty teaching force for the United Arab Emirates. Journal of education for teaching. 1995, 1:289-301.

8. Bener A, Breger E, al-Falasi AS. Risk taking behaviour in road traffic accidents. Joumal of traffic medicine, 1994, 23(2): 65-70.
9. Mcllvenny S. Fatigue in a develooing country [Thesis]. Belfast, United Kingdom, Queen's University, 1998:5-14.

10. Margolis SA, Reed RL. ECG analysis skills of family medicine residents in the United Arab Emirates: a comparison with US data. Family medicine. 2001, 33(6): 447-52.

11. Margolis SA, Reed RL. Institutionalized oldor adulte in a hoalth district in tho United Arab Emirates: health status and utilization rate. Gerontology, 2001, 47(3): 161-7.

12. Schrier RW. Geriatric medicine. Philadelphia, WB Saunders, 1990:1.

13. Noor AMM, ed. Annual report: Preventative Medicine Department. United Arab Emirates, Ministry of Health, 1989.

14. Noor AMM, ed. Annual report: Preventative Medicine Department. United Arab Emirates, Ministry of Health, 1999.

15. The World Fact Book. Washington DC, Central Intelligence Agency, 2000 (accessed 30 Jan 2001 at http://www.odci. gov/cia/publications/factbook/).

16. Emergency care guidelines. Dallas, Texas, American College of Emergency Physicians, 1996 (Policy \# 400057).

17. Olson EJ. No room at the inn: a snapshot of an American emergency room. Stanford law review, 1994, 46(2):449-501.

18. McNamara $P$, Witte $R$, Koning A. Patchwork access. Primary care in EDs on the rise. Hospitals, 1993, 67(10):44-6 